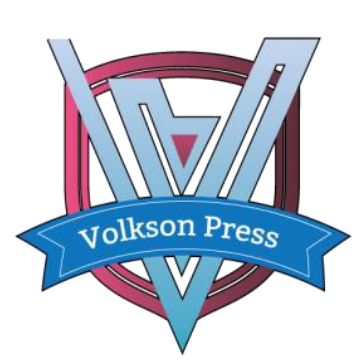

Contents List available at VOLKSON PRESS

Economics \& Management Innovations(EMI)

DOI : http://doi.org/10.26480/icemi.02.2018.38.40

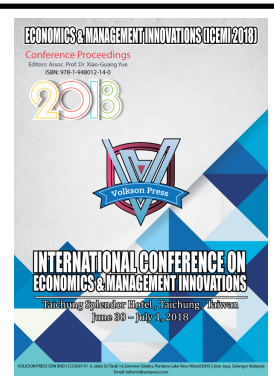

ISBN: 978-1-948012-14-0

\title{
AN EMPIRICAL STUDY ON THE INFLUENCING FACTORS OF THE PRICE OF LISTED COMPANIES IN THE BELT AND ROAD CONCEPT - - DATA ANALYSIS BASED ON 2010-2018
}

\author{
Yong Zheng ${ }^{1,2,3}$ \\ ${ }^{1}$ School of Economics Shanghai University, BaoShan district on the main road no. 99, Shanghai City, China. \\ ${ }^{2}$ Ctrip Computer Technology (Shanghai) Co., Ltd, \\ ${ }^{3}$ ChangNing district Jin Zhong road no. 968, Shanghai City, China \\ *Corresponding Author Email: brain1314@icloud.com
}

This is an open access article distributed under the Creative Commons Attribution License, which permits unrestricted use, distribution, and reproduction in any medium, provided the original work is properly cited.

\section{ARTICLE DETAILS}

\section{Article History:}

Received 26 June 2018

Accepted 2 July 2018

Available online 1 August 2018

\section{ABSTRACT}

This paper uses the data of all listed company stocks in the A-share market to construct factor models. Based on the stock market quotation from April 2010 to April 2018, the Fama-Frech 3-factor model analysis method is applied to the application of the One Belt One Road concept stock pricing. By improving the model, introducing big data indicators, constructing a new theoretical model, and using the method of econometrics to empirically analyze the economic factors that affect the price of the Belt and Road concept stock. Pearson test, variance inflation factor test, White test and other test methods were used to test the robustness of the model, and the pricing model of the influencing factors of the One Belt One Roadconcept stock price was finally obtained. Analyze and evaluate the model, combine the fact, make further research on the concept development strategy of China's One Belt and One Road.

\section{KEYWORDS}

Fama-Frech3 factor model, Big data factor, Multiple regression analysis, One Belt and One Road concept stock.

\section{INTRODUCTION}

China has become the second largest economy in the world. According to the statistics of the National Bureau of Statistics, China's GDP in 2017 reached 82.71 trillion yuan (approximately 12.738 trillion U.S. dollars), which accounted for approximately 65.6\% of the US' GDP in 2017 (approximately 19.387trillion U.S. dollars). President Xi Jinping proposed the concept of "One Belt and One Road" concept in 2013. This article uses the Python programming language to construct an econometric pricing model and uses the statsmodels library for regression analysis. After massive calculations of raw data, various factor models are constructed to find out the concept of "One Belt and One Road" stocks. Pricing influencing factors, and conducting empirical research, finally combined with big data factors to improve the model, and further strengthen the interpretation of the model.

\section{RELATED LITERATURE REVIEW}

Reading the relevant literature, Fama and French proposed the threefactor model in 1993 based on the APT theory of one of the modern financial components, followed by an empirical test of the 13 major stock markets in the world, and 12 results were good. , further enhance the persuasiveness of the model. The concept of China's One Belt and One Road has been proposed for five years. However, there has been very little research on related stocks along the way. Most of the articles are based on the One Belt One Road concept policy and macro strategic issues. Among them, "Empirical Study on the Performance of the Related Industries under the "One Belt and One Road" Program-Based on Event Research Method and Event Study Method. "Study on Tail Risk Linkage between the "One Belt and One Road" Sector and the Shanghai and Shenzhen Stock Exchange Main Board Stock Indices" focused on tail risk research [1,2]. However, there is no positive research on the pricing factors of the related stocks of the One Belt and One Road, so how the Fama-Frech model interprets the concept of the One Belt One Road concept stock will be a very meaningful study.

\section{THE ONE BELT AND ONE ROAD CONCEPT STOCK PRICE INFLUENCE FACTOR SELECTION}

The data in this paper is mainly derived from public data of Ricequant and some data of wind database. Using the complete 8-year statistics from April 2010 to April 2018, this paper follows the method of Fama-French constructing the factor. First, all the stocks of the A-shares are ranked in ascending order of the total market value, and the top $50 \%$ are taken as the small-scale stock group, which is denoted as S group (Small), and the bottom $50 \%$ is designated as large-scale company stock, which is recorded as B group (Big) [3]. Similarly, arranging all the stocks of the Shanghai Ashares in accordance with the market-to-book ratio, taking the top $30 \%$ as growth stocks, and writing them into the L group (Low). The last 30\% of the stocks are designated as value stocks, For Group H(High). The results obtained from the above two stock classifications are combined into two portfolios to form six portfolios, namely B/H, B/M, B/L, S/H, S/M, and S/L. Reconstructing SMB (Small minus Big) indicates the scale factor, which means the weighted average returns of small-scale stock portfolios $(\mathrm{S} / \mathrm{L}$, $\mathrm{S} / \mathrm{M}, \mathrm{S} / \mathrm{H}$ ) and the weighted average returns of large-scale stock portfolios (B/L, B/M, B/H) Differenceaverage number of returns-weighted averages; constructing HML(High Minus Low) as a value factor, High Value Portfolio $(\mathrm{S} / \mathrm{H}, \mathrm{B} / \mathrm{H})$ and Growth Portfolio (S/L (B, L) The difference between the weighted average returns. In addition, the Big Data Index was selected as the new comprehensive factor BigData (BigD) from the Wind database [4].

\section{THE ESTABLISHMENT AND TEST OF THE MODEL}

\subsection{OLS method estimation model}

This paper uses an ordinary least squares (OLS) estimator to analyze and correlate the above four indicators with the average return ratio of the One 
Belt One Road concept stocks. First, a multiple linear regression model was constructed as follows:

$$
\begin{aligned}
R i t-R f t=a i+\beta i & (R m t-R f t) \\
& +s i S M B t+h i H M L t+\text { BigDt } \\
& +\varepsilon i t
\end{aligned}
$$

Using Python programming, using all the stock market data, using the closing price to calculate the monthly yield of each stock, using the book value per share and market price to get the book value ratio of each stock price, and then use the market value weighted calculation The total yield of each group of stocks, then use S group minus B group to get SMB factor, $\mathrm{H}$ group minus L group to get HML factor, use CSI 300 index as market data to calculate market return, then subtract no risk The interest rate (threemonth Treasury bond interest rate/12), which derives the market value factor, uses the Big Data Index to calculate the return rate of the Big Data Index. Descriptive statistics, such as Table 1:

Table 1: Descriptive Statistics for Each Factor

\begin{tabular}{|l|l|l|l|l|l|}
\hline & HML & Rm_Rf & SMB & BigData & $\mathrm{y}$ \\
\hline count & 95 & 95 & 95 & 95 & 95 \\
\hline mean & -0.003565 & 0.002328 & -0.014949 & 0.030269 & 0.006735 \\
\hline std & 0.022477 & 0.073005 & 0.063104 & 0.138394 & 0.07971 \\
\hline
\end{tabular}

Using pandas to construct a DataFrame, calculate the pearson correlation coefficient: as shown in Table 2:

Table 2: Correlation coefficient of HML-SMB factor

\begin{tabular}{|l|l|l|l|l|}
\hline & HML & Rm_Rf & SMB & BigData \\
\hline HML & 1 & 0.745663 & -0.676646 & 0.203096 \\
\hline Rm_Rf & & 1 & -0.971888 & 0.560603 \\
\hline SMB & & & 1 & -0.647212 \\
\hline
\end{tabular}

The correlation coefficient between the explanatory variables is large, especially the correlation coefficient of the market value factor $\mathrm{Rm} \_\mathrm{Rf}$ is greater than 0.8 , so the model has a linear correlation. Then, is there any multicollinearity? First, the four factors are regressed, and then the variance inflation factor (VIF) is tested. As shown in Table 3:

Table 3: VIF of each factor

\begin{tabular}{|l|l|}
\hline Intercept & 1.85 \\
\hline HML & 2.7 \\
\hline Rm_Rf & 25.5 \\
\hline SMB & 25.3 \\
\hline BigD & 2.19 \\
\hline
\end{tabular}

It shows that there is multicollinearity between $\mathrm{Rm} \_\mathrm{Rf}$ and SMB factors.

\subsection{Rejection of variables}

In order to eliminate multicollinearity, regression is performed using a method that removes the more relevant variables. From the model estimation results, we can see that the market value factor of $\mathrm{Rm}$ Rf has the worst significance to the model, that is, the market value factor has the smallest impact on the concept of the One Belt and One Road concept stock price. It does not consider it first. Therefore, after removing the Rm_Rf factor, the model is rebuilt to perform OLS regression. The regression results are shown in Table 4:
Table 4: Regression model after removing $R m_{-} R f$ factor

\begin{tabular}{|l|l|l|l|}
\hline Dep. Variable: & $\mathrm{y}$ & R-squared: & 0.891 \\
\hline Model: & OLS & Adj. R-squared: & 0.887 \\
\hline Method: & Least Squares & F-statistic: & 246.7 \\
\hline Date: & Sat, 16 Jun 2018 & Prob (F-statistic): & $1.41 \mathrm{E}-43$ \\
\hline Time: & 0.879918981 & Log-Likelihood: & 211.06 \\
\hline No. Observations: & 95 & AIC: & -414.1 \\
\hline
\end{tabular}

The T-test significance of each factor is shown in Table 5:

Table 5: Regression model T-value table after rejecting $\mathrm{Rm} \_\mathrm{Rf}$ factor

\begin{tabular}{|l|l|l|l|l|l|l|}
\hline & coef & std err & $\mathrm{t}$ & $\mathrm{P}>|\mathrm{t}|$ & {$[0.025$} & $0.975]$ \\
\hline Intercept & -0.0063 & 0.003 & -2.03 & 0.045 & -0.012 & 0 \\
\hline HML & 0.5025 & 0.184 & 2.732 & 0.008 & 0.137 & 0.868 \\
\hline SMB & -1.1787 & 0.084 & -14.008 & 0 & -1.346 & -1.012 \\
\hline BigD & -0.0936 & 0.029 & -3.245 & 0.002 & -0.151 & -0.036 \\
\hline
\end{tabular}

Then we need to test the factor inflation factor(VIF) of each factor again. The test results are shown in Table 6:

Table 6: VIF Table of Regression Model after Rejection of Rm_Rf Factor

\begin{tabular}{|l|l|}
\hline Intercept & 1.26 \\
\hline HML & 2.24 \\
\hline SMB & 3.69 \\
\hline BigD & 2.09 \\
\hline
\end{tabular}

After eliminating the Rm_Rf factor, the VIF of each factor is less than 10, and there is no multicollinearity between the factors. The model coefficient R2 is 0.891 , and the correctable coefficient R2 is 0.887 , indicating that the goodness of fit of the model is good; $F=247.7>F(3,91)$, indicating that the model is significant [5]. Use t-values to test the significance of the regression parameters. When $\alpha=0.05$ and $k=3$, $\mathrm{t} 0.025(95-\mathrm{k})=\mathrm{t} 0.025(92)=1.987$, and the estimated values of the regression coefficients of each explanatory variable were passed the t-test.

\subsection{Autocorrelation Test}

First use the scatter graph to roughly determine whether there is autocorrelation, as shown in Figure 1:

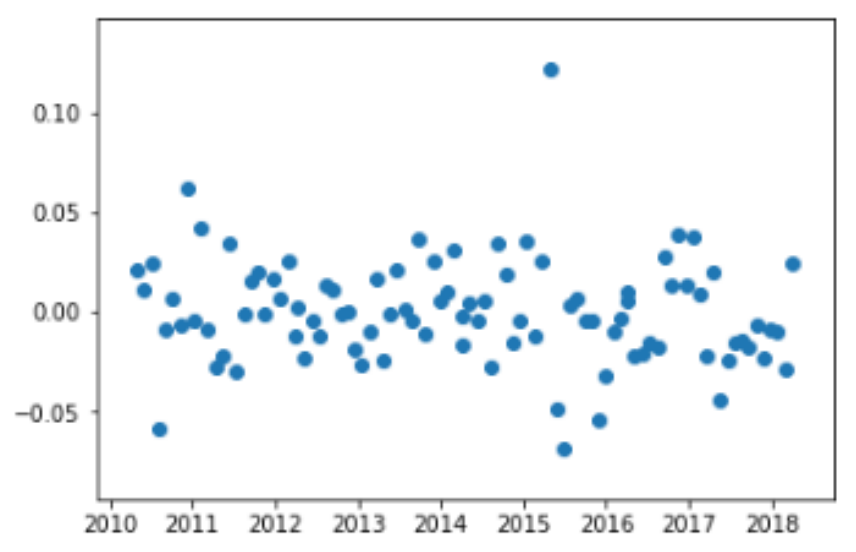

Figure 1: Scatter plot of residual items 
According to the distribution residuals, there may be autocorrelation. Therefore, the $\mathrm{D}-\mathrm{W}$ model is used for autocorrelation test. The regression results obtained are shown in Table 7:

Table 7: Table of DW Values for Regression Models after Rejection of Rm_Rf Factor

\begin{tabular}{|l|l|l|l|}
\hline Omnibus: & 25.329 & Durbin-Watson: & 1.945 \\
\hline Prob (Omnibus): & 0.000 & Jarque-Bera (JB): & 73.495 \\
\hline
\end{tabular}

It is known that the value of the above-mentioned model DW test is 1.945. The sample selected in this paper is $\mathrm{n}=95, \mathrm{k}=3$, and $\alpha=0.05$. Lookup table $d L=1.602, d U=1.732$. Since $d U<D W<4-d U$, the result of the $D-W$ test is accepted as $\mathrm{H} 0$, ie, there is no correlation between the pre- and postperturbation terms, ie there is no autocorrelation in the disturbance term. The resulting model is as follows:

$$
\begin{aligned}
\text { Rit }-R f t=-0.0063 & +0.5025 \mathrm{HMLt} \\
& -1.1787 \mathrm{SMB}-0.0936 \mathrm{BigDt}
\end{aligned}
$$

Among them, the coefficient of determination is $\mathrm{R} 2=0.891$, the correctable coefficient of correction is $\mathrm{R} 2=0.887, \mathrm{~F}=246.7$, and $\mathrm{n}=95$.

\section{ANALYSIS AND SUMMARY OF THE MODEL}

\subsection{Explanation of Economic Significance}

The modified coefficient of the model reached 0.891 , indicating that the model fits well to the sample and can account for $89.1 \%$ of the variance. As can be seen from the model, the three factors of book value-to-market ratio factor (HML), scale factor (SMB), and big data factor (BigData) have a significant effect on the yield of the "One Belt and One Road" concept stock. Moreover, the coefficient of book value-to-market ratio factor (HML) is positive, which indicates that the yield ratio of the "One Belt and One Road" concept stock is positively correlated with the factor ratio of book value. SMB, BigData's coefficient is negative, indicating that the scale factor (SMB), BigData factor (BigData) is negatively related to the yield of the One Belt One Road concept stocks [6].

The actual significance of the analysis model shows that in this model, the ratio of the book-to-market capitalization ratio changes by $1 \%$, and the return rate of the one-way-one-belt concept stock changes by $0.5025 \%$; when the scale factor increases by $1 \%$, on average, the concept of stocks of the One Belt and One Road The yield dropped by $1.1787 \%$; when the big data index increased by $1 \%$, on average, the yield of the One Belt One Road concept stock fell by $0.0936 \%$.

\subsection{Overall economic significance of the model}

You can refer to the model and make a reasonable estimate of the trend of the yield of the One Belt and One Road concept stock based on the changes in the ratio of the book market value ratio factor, the scale factor, and the big data factor, and then taking into account other factors. This helps individual or institutional investors decide their own investment strategies, and it also helps in the implementation of relevant policies of state agencies.

\subsection{Tations and Improvements of the Model}

This paper examines the Fama-Frech multifactorial model of the factors affecting the yield of the One Belt and One Road concept stocks, and improves the Fama model. It can be combined with the concept of the One Belt One Road concept to propose changes in the return rate of stocks before and after. Conduct further research to reveal the impact of the One Belt One Road Conceptual Strategy on the Chinese economy.

\section{REFERENCES}

[1] Jingqun, S. 2017. An Empirical Study on the Performance of Stocks in Related Industries under the Belt and Road -Based on the Event Study Method [J]. Times Finance.

[2] Jingyi, L. 2016. A study on the tail risk linkage between the "One Belt and One Road" sector and the returns of stock index of Shanghai and Shenzhen stock exchanges [J]. Journal of Wuhan University of Technology (Information \& Management Engineering).

[3] Qing, M., Hongxing, Y. 2016. "One Belt and One Road" concept stock price associated network model and application [J]. Finance and Accounting Monthly, 2016.

[4] Zhibing, L., Guangyi, Y., Yongchang, F., Liang, J. 2017. Empirical test of the Fama-French five-factor model in the Chinese stock market [J]. Financial Research.

[5] Sundqvist, T. 2017. Tests of a Fama-French Five-Factor Asset Pricing Model in the Nordic Stock Markets (Available on Internet) [J]. Hanken School of Economics.

[6] Fama, E.F., French, K.R. 2016. International tests of a five-factor asset pricing model [J]. Journal of Financial Economics,2016. 